\title{
The Role of Renal Macrophages in the Aglomerular Kidney of the Sea-Horse (Teleost) in the Removal of Exogenous Macromolecules from Circulating Blood
}

\author{
Tadashi TsuJII \\ Department of Anatomy, Okayama University School of Medicine and Division of Ultrastructure Research, Shigei Medical \\ Research Institute, Okayama, Japan
}

Received April 25, 1988

Summary. Mechanisms involved in the removal of exogenous macromolecules from circulating blood were investigated in the aglomerular nephrons of the kidney of the sea-horse, Hippocumpus kuda Bleeker, using either native anionic or cationized probes.

After intraperitoneal injection of native anionic horse-spleen ferritin (HS-AF) or cationized one (HSCF) into the sea-horse, kidneys and gills were examined morphologically at intervals of $1 \mathrm{~h}$ to 14 days. Histochemical and immunohistochemical studies and transmission electron microscopy of the kidneys revealed that most of the injected HS-AF or HS-CF were taken up by macrophages in the sinusoids of hemopoietic tissue through pinocytosis, being gradually accumulated into their phagolysosomes. By the 14 th day, the injected ferritin particles were degraded and the ferric agglomerates were concentrated within the phagolysosomes. Then the macrophages heavily laden with densely packed ferric catabolites migrated into the hemopoietic area forming macrophage agglomerates or macrophage centers. Some HS-AF and HS-CF particles infiltrated into the tubular basement membrane, where they were taken up by the tubular epithelial cells through pinocytosis, translocated into the phagolysosomes, fragmented into small ferric catabolites and then excreted into the urinary space.

In contrast, examination of the gills revealed neither HS-AF, HS-CF particles nor their histochemically detectable ferric catabolites in either the interstitial space including basal lamina or the alveolar epithelia. It seems that no appreciable egress of exogenous substances occurs from the gill into the environmental water.

It has been shown that in the mammalian kidney, the glomerular capillary wall and mesangium work to remove the immune complexes, protein aggregates, and inert macromolecular probes passed out across the capillary wall or deposited at various sites of the glomerular tufts (BRENNER et al., 1977; SHARON et al., 1977; PURTELL et al., 1979; TAKAMIYA et al., 1979; MiCHAEL et al., 1980; KEANE and RAIJ, 1980, 1981; CATtell et al., 1982; STERzEL et al., 1983a, b; GoOdE et al., 1984; TSUJIl et al., 1985; BERTOLATUS and HUNSICIKER, 1985; SEILER et al., 1986).

Fish kidneys also have nephrons, which however accompany hemopoietic tissue provided with melanomacrophage centers (ROBERTS, 1975; ELLIS et al., 1978). They make a negligible contribution to the excretion of nitrogenous metabolites, which are mainly cast off through the gills as ammonia or ammonium ions (HOAR, 1975; RANKIN et al., 1983). As is well known, marine teleosts have generally smaller glomeruli than freshwater ones. Indeed, some marine teleosts have no glomeruli in their kidneys (OGAWA, 1957; ERICSSON and TRUMP, 1969; HICKMAN and TRUMP, 1969; BABIKER and RANKIN, 1979), but it is unknown whether these aglomerular kidneys have the ability to dispose of immune complexes and other exogenous macromolecules introduced into circulating blood just as in glomerular kidneys. If they have such a function, it may be of interest to determine how they eliminate the catabolites.

In order to elucidate this, the author introduced HS-AF and HS-CF particles into sea-horses having aglomerular kidneys. These heterologous ferritin particles, which were originally introduced by FAR QUHAR et al. (1961) and RENNKE et al. (1975), were deemed suitable for the present examination, because they give no inflammatory or chemotactic stimuli and have the advantage of being detected immunohistochemically by a ferritin antibody, and electron microscopically by its specific figures. The decomposed products also give a distinct Prussian blue reaction (STERZEL et al., 1983b). HS-AF and HS-CF particles 
are also useful for the observation of different biological reactions against the cationic and anionic macromolecules.

In this paper, it shall be demonstrated that the macrophages in the sinusoid of hemopoietic tissue of the aglomerular sea-horse kidney remove most of the circulating ferritins by pinocytosis, decompose them in their phagolysosomes, and that those laden with a mass of degradation ferric products are aggregated to form clusters, which may be the melanomacrophage center. Gills participate only neglibly in the excretion of the ferritin, though some excretory activities have been observed in renal tubules.

\section{MATERIALS AND METHODS}

Thirty-two healthy male and female sea-horses, Hippocumps kuda Bleeker, weighing 10-20 g and 130$170 \mathrm{~mm}$ in length were used. They were given courtesy of Shima Marineland (Kashikojima, Ago-cho, Mie Prefecture), and used within two days of delivery. The fish were kept in aerated seawater tanks $(10 l)$ without food at $22-24^{\circ} \mathrm{C}$. The seawater was changed every $3 \mathrm{~h}$ in all the tanks. Before use the fish were divided into three groups, 4,4 and 24 specimens in groups I, II and III respectively; those in the first group received no treatment and served for general morphologic observations, those in the second group were used for the perfusion test of kidneys with the cationic probes for the detection of anionic sites, and those in the third group received intraperitoneal injections of HS-AF or HS-CF.

\section{General morphologic observations and histochemical staining}

Four specimens in group I were used for normal morphological observation at the light- and electronmicroscope levels. One half of the kidney and gill was used for light microscopy and the other half for electron microscopy. The tissues were fixed in Zamboni's fixative (ZAMBONI and DEMARTINO, 1967), embedded in paraffin, sectioned and stained with hematoxylineosin for general microscopy, Prussian blue for the detection of ferric iron, Feulgen reaction for DNA, and immunohistochemical staining for ferritin.

\section{Immunohistochemical detection of ferritin}

The horseradish peroxidase-antiperoxidase (PAP) method (STERNBERGER et al., 1970) was employed. The

Fig. 1, a-p. Light micrographs of aglomerular kidney tissues of sea-horses showing hemopoietic cells, renal tubule ( $\sum_{w}$ ), melano-macrophage center ( ) and melanin pigments. a-d. Tissues from healthy fish. a. A thin section of resin-embedded tissue stained with toluidine blue. b. High power magnification of Figure a, showing macrophages. c. A paraffin section stained with Prussian blue. No reaction products are visible. d. The same tissue as in Figure $\mathrm{c}$ showing ferritin immunostained with PAP method. No reaction products are visible on the tissue. e-h. Sea-horses sacrificed $1 \mathrm{~h}$ after intraperitoneal injection of $0.5 \mathrm{ml}$ of HS-CF. e. Fine brownish granules in macrophages stained with hematoxylin-eosin. f. The same tissue as in Figure e but stained with Prussian blue. Reaction products are visible throughout the hemopoietic tissue. $\mathbf{g}$. Higher magnification of Figure e. The granules in macrophages are stained in blue, but no reaction is recognized on the tubular epithelia, hematopoietic cells, melanin pigments or on the melano-macrophage center. $\mathbf{h}$. The same tissue as in Figure e, but showing immunostained ferritin. Reaction products are visible on the granules of the macrophages and those of some hemopoietic cells, but no reaction products occur on the tubular epithelia, melanin pigments or on the melano-macrophage center. i-l. Sea-horse sacrificed $1 \mathrm{~h}$ after the last intraperitoneal injection of the ferritin-overload experiments; the fish received a total $1.2 \mathrm{ml}$ of $1 \% \mathrm{HS}-\mathrm{AF}$. i. Brownish color large granules within macrophages stained with hematoxylin-eosin. j. The same tissue as in Figure i, but stained with Prussian blue. Reaction products are darker blue than in Figure f. k. Higher magnification of Figure i. The granules in the macrophage are stained dark blue, and the fine granules and melanin pigments are also in light blue. 1. The same tissue as in Figure $i$, but showing immunostained ferritin. A strongly positive reaction is visible on the granules in the macrophages, and a weak reaction on some macrophages of the melanomacrophage center. m-p. Sea-horse sacrificed 14 days after the last injection of the ferritin-overload experiment. The fish received a total $1.2 \mathrm{ml}$ of $1 \% \mathrm{HS}$-AF. $\mathbf{m}$. Hematoxylin-eosin stained tissue, showing that the granules containing macrophages located around the tubules found in Figures e and i have disappeared; the macrophages in the melano-macrophage center are stained a light brownish red. $\mathbf{n}$. The same tissue as in Figure $\mathrm{m}$, but stained with Prussian blue. Reaction products are found only on the melano-macrophage center. o. High power picture of Figure n. No reaction products are detected within the macrophages located around the tubules, but a strong reaction is found on the macrophages of melano-macrophage center. p. The same tissue as in Figure $\mathrm{m}$, but stained with ferritin. No reaction products are visible. a, f, j, n: $\times 165 ; \mathrm{b}-\mathrm{e}, \mathrm{g}-\mathrm{i}, \mathrm{k}-$ m, o-p.: $\times 825$ 

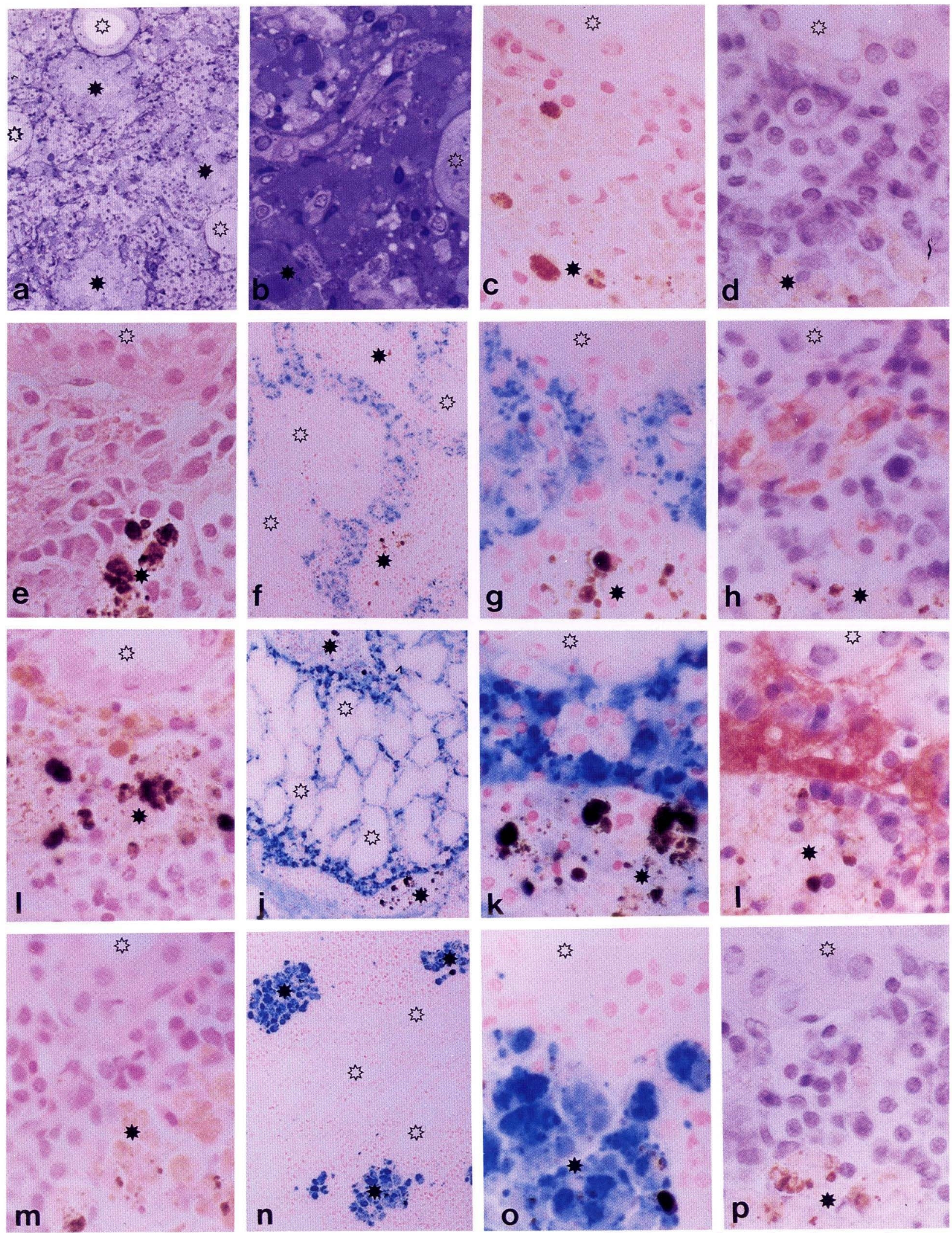

Fig. 1, a-p. Legend on the opposite page 
paraffin embedded tissue sections, about $3 \mu \mathrm{m}$-thick, were stained with rabbit IgG against horse spleen ferritin and then treated with a PAP Kit (Dako, Santa Barbara, CA, USA: System 40).

Perfusion of kidneys with cationic cacodylate-iron colloid ( $\mathrm{Fe}$-Cac) to detect the anionic barrier

The specimens in group II were anesthetized by adding MS-222 (Sankyo Co., Tokyo) to the seawater in the tank $(2 l)$ at a final concentration of $0.05 \%$; the peritoneal cavity was then opened, and the cardiac ventricle was cannulated. Through the cannula the whole body was perfused with physiological saline solution at $40 \mathrm{mmHg}$ for $2 \mathrm{~min}$ to remove the blood, and then with $2 \mathrm{ml}$ of $\mathrm{Fe}-\mathrm{Cac}, \mathrm{pH} 7.3$, adjusted to 270 milliosmols with glucose for $15 \mathrm{~min}$, using the method described previously (SENO et al., 1983a; TsuJII et al., 1984a, b). The specimens were once more perfused with physiological saline to remove the unbound $\mathrm{Fe}-\mathrm{Cac}$. The kidneys were then removed and fixed for morphologic observations.

\section{Intraperitoneal injection of $H S-A F$ or $H S-C F$}

The 24 specimens in group III were divided further into subgroups III-a, b, c, d and III-a', b', c', d', with three specimens each. Those from the group IIIa, b, c, $\mathrm{d}$ were injected with HS-AF and those from the group IIIa', $b^{\prime}, c^{\prime}, d^{\prime}$ with HS-CF, $0.5 \mathrm{ml}$ of $1 \%$ HS-AF or HS-CF solution in saline per fish. The specimens of IIIa and IIIa' were sacrificed $1 \mathrm{~h}$, and IIIb and IIIb' 24 $\mathrm{h}$ after injection. Those in group IIIc, $d$ and $c^{\prime}, d^{\prime}$ served for the ferritin-overload experiments; each specimen received six injections of $0.2 \mathrm{ml}$ of $1 \%$ HS-AF saline solution (c, d) or HS-CF saline $\left(c^{\prime}, d^{\prime}\right)$ at $1 \mathrm{~h}$ intervals, $1.2 \mathrm{ml}$ in total. One hour after the last injection the specimens in IIIc and $c^{\prime}$ were sacrificed, and those in IIId, $d^{\prime}$ were kept two weeks after the last injection under ideal physiological conditions at Shima Marineland and then sacrificed. After sacrifice the kidneys and gills were removed and used for morphologic observations.

\section{Routine electron microscopy}

The tissues were fixed in Karnovsky's fixative (KAR NOVSKY, 1965) at $0^{\circ} \mathrm{C}$ for $2 \mathrm{~h}$. After fixation, specimens were washed in $0.05 \mathrm{M}$ sodium cacodylate buffer ( $\mathrm{pH}$ 7.3) containing $0.3 \mathrm{M}$ sucrose, postfixed in $2 \%$ $\mathrm{OsO}_{4}$ in $0.05 \mathrm{M}$ sodium cacodylate buffer $(\mathrm{pH} 7.3)$ containing $0.2 \mathrm{M}$ sucrose, at $0^{\circ} \mathrm{C}$, for $3 \mathrm{~h}$, dehydrated through graded alcohol to acetone, and embedded in TAAB resin (TAAB Lab., Reading, England). Thin sections and ultra-thin sections were then obtained by a diamond knife on a Reichert OmU-3 ultratome. After examining thin sections by light microscopy staining with toluidine blue, these ultra-thin sections, unstained or contrasted with uranyl acetate and lead citrate, were examined in a Hitachi H-700 transmission electron microscope at an accelerating voltage of $75 \mathrm{kV}$.

\section{Preparation of $H S-A F, H S-C F$ and rabbit $\operatorname{Ig} G$ anti- $H S-A F$}

HS-AF was prepared from horse spleens by the method of VOGT et al. (1968), thus avoiding the introduction of cadmium. This material was free of apoferritin and was stored under sterile conditions at $4^{\circ}$ C. Ferritin was estimated by its absorbance at $440 \mathrm{~nm}$ $\left(\mathrm{E}_{440}=16.2\right)$.

Cationization of HS-AF was done by the method of BATSFORD et al. (1980), based on the method of DANON et al. (1972). The grade of cationization was determined by isoelectric focussing in a $4.7 \%$ acrylamide dish gel containing 2\% Ampholine, $\mathrm{pH}$ 3.5-10.0 (LKB, Broma, Sweden), revealing an isoelectric point (pI) over 10.0.

Antisera to ferritin was raised in rabbits by single immunization with $1 \mathrm{mg}$ of HS-AF in Freund's complete adjuvant (DIFCO Lab, Detroit, MI, USA) subcutaneously. The rabbits were bled out two weeks after the injection. The IgG fraction in the antisera was precipitated with a $40 \%$ saturation of ammonium sulfate. The precipitate was dialyzed against phosphate buffered saline and purified through an af-

Fig. 2, a-b. Low-power electron micrograph showing tubular epithelia, hemopoietic tissue (a) and melanomacrophage center (b) of the same sea-horse as shown in Figure 1a. Many large phagolysosomes (arrows) are seen in the macrophages $(m)$. The area in the box is illustrated at higher magnification in Figure 3 . $e p$ Tubular epithelium, $n$ nucleus, $t$ tubular basement membrane, $t>$ lumen of renal tubule, $p$ melanin pigments. Stained with uranyl acetate and lead citrate. $\times 4,000$

Fig. 3. Higher magnification of the area boxed over the phagolysosome in the macrophage shown in Figure 2a; heterochromatin $(h)$ and fibers of euchromatin $(e)$ of phagocytosed cell. In light microscopic studies, a positive Feulgen reaction is detected on heterochromatin. $\times 60,000$

Fig. 4. Higher magnification of a part of the phagolysosomes of the macrophage from the same section as shown in Figure $2 \mathrm{~b}$. The picture shows the melanin pigments $(p)$, condensed fibers $(f)$ and heterochromatin (h). $\times 60,000$ 


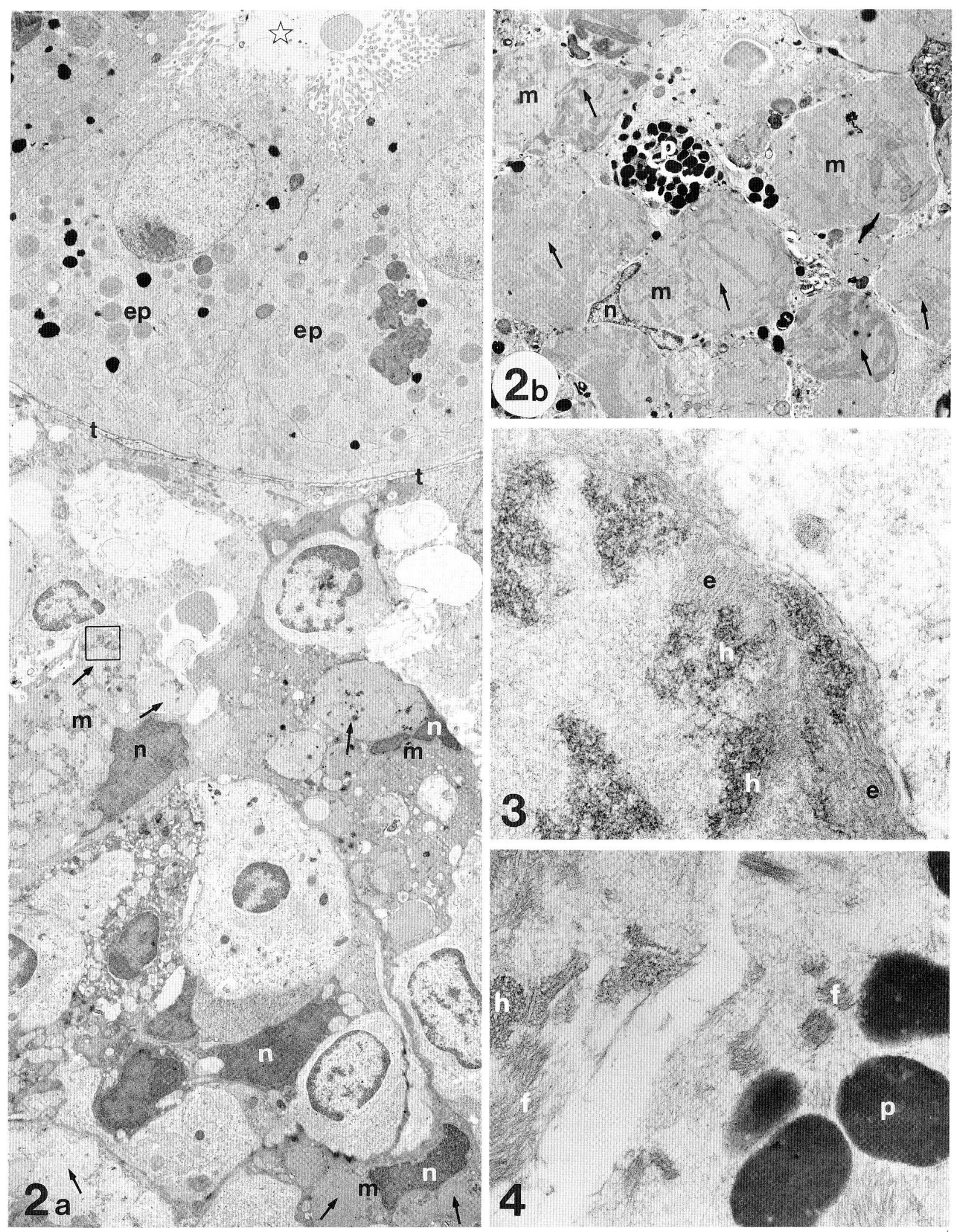

Fig. 2-4. Legends on the opposite page. 
finity column with HS-AF coupled to $20 \mathrm{~g}$ Sepharose $4 \mathrm{~B}$.

\section{RESULTS}

Light microscopy of hematoxylin-eosin and toluidine blue stained sections from untreated fish revealed that sea-horse kidneys have no glomeruli (Fig. 1a). The renal tissue was organized with loosely packed tubules and hemopoietic tissue having melano-macrophage centers. The sinusoids of hemopoietic tissue also contained numerous macrophages (Figs. 1b-e, g-i, k-m, $o-p)$, some of which showed Feulgen positive granules in phagolysosomes. The melano-macrophage centers were dense agglomerates of macrophages laden with many granular substances and some melanin pigments. They appeared generally pale red in hematoxylineosin and pale blue in toluidine blue stained sections; some of them contained dark brown melanin pigments. The nuclei were often invisible, although irregularly shaped ones compressed by heavy-laden phagocitized materials were occasionally seen (Figs. 1b-e, g-i, k$\mathrm{m}, \mathrm{o}-\mathrm{p}$ ).

The renal tubules were composed of two parts: the proper renal tubules and the collecting tubules, which could be distingushed morphologically from each other.

Observations of hematoxylin-eosin sections $1 \mathrm{~h}$ after intraperitoneal injection of HS-AF or HS-CF, revealed fine, light brown granules in the cytoplasm of macrophages in the sinusods of hemopoietic tissue around the tubules (Fig. 1e). One hour after the last injection of the ferritin-overload experiments, the granules in the macrophages became distinct, increasing in size with a change in color to reddish orange. However, macrophages found within the melanomacrophage centers had no such granules (Fig. 1i). Fourteen days after the injection, these reddish orange colored granules disappeared from the macrophages those either in the sinusoids or the hemopoietic focuses, while those in the melano-macrophage centers showed pale brownish granules of a pink color (Fig. 1m).

Observations of the tissues of healthy fish stained with Prussian blue revealed no positive ferric reactions within the tubular lumen or on the epithelia and macrophages in either hemopoietic tissue or melanomacrophage centers (Fig. 1c). After the injection of $0.5 \mathrm{ml}$ of HS-AF or HS-CF, however, those macrophages found in the sinusoids of hemopoietic tissue gave a positive reaction but no Prussian blue reaction in the tubules or the macrophages in the melanomacrophage centers, though some of them had melanin pigments (Figs. 1f, g). The heavy deposition of iron granular form was noted in the hemopoietic cells $1 \mathrm{~h}$ after the last injection of the ferritinoverload experiments and $24 \mathrm{~h}$ after the ferritin injection of $0.5 \mathrm{ml}$ of ferritin (Figs. 1i, k). At this stage, fine Prussian blue positive granules were also detected within the macrophages in melano-macrophage centers. Some of their melanin pigments also gave a slightly positive ferric reaction (Fig. $1 \mathrm{k}$ ). In contrast, the tubular epithelia gave hardly any ferric reaction (Fig. 1k). Fourteen days after the ferritin injection, the staining pattern for iron in the macrophages was granular, but a positive ferric reaction was detected only within the macrophages in melanomacrophage centers (Figs. $1 \mathrm{~m}$, o). Their melanin pigments also gave a positive ferric reaction.

In the gills, within $1 \mathrm{~h}$ after the injection of HS-AF or HS-CF, infiltrating white blood cells and blood serum in the capillaries gave a positive ferric reaction while the alveolar epithelia did not.

One hour after the intraperitoneal injection of 0.5 $\mathrm{ml}$ of HS-CF, the renal tissue revealed a moderately positive immunoreactivity for ferritin in the sinusoids of hemopoietic tissue with the macrophages having ferritin granules. Some hemopoietic cells also possessed slightly positive granules, but no positive reaction was found within the macrophages in melanomacrophage centers, nor in the tubules (Fig. 1h). However, HS-AF particles were taken up only by the macrophages. The strongest reaction was observed 1 $\mathrm{h}$ after the last injection of the ferritin-overload experiments. The macrophages in the sinusods of hemopoietic tissue were stained deep red but the macrophages in melano-macrophage centers were not distinctly stained, though they had fine ferritin positive granules (Fig. 11). Fourteen days after the injection of ferritin, none of the macrophages in the hemopoietic tissue or those in the melano-macrophage center showed any ferritin positive granules (Fig. 1p). These findings were comparable to those of the healthy controls (Fig. 1d).

Electron microscopy of the renal tissue of the healthy controls revealed the detailed structure of renal tubules composed of cuboidal to columnar epithelia. Among these, two cell types could be distinguished: the epithelia equipped with abundant mitochondria and conspicuous basal infoldings, and those poor in both mitochondria and basal infoldings but abundant in granules and phagolysosomes containing light and electron dense materials (Fig. 2a). The former is characteristic of the collecting tubules, and the latter, proper tubules. The tubular basement membrane was $1,000-5,000 \mathrm{~nm}$ thick, but lacked any visible structural components, and was covered by 

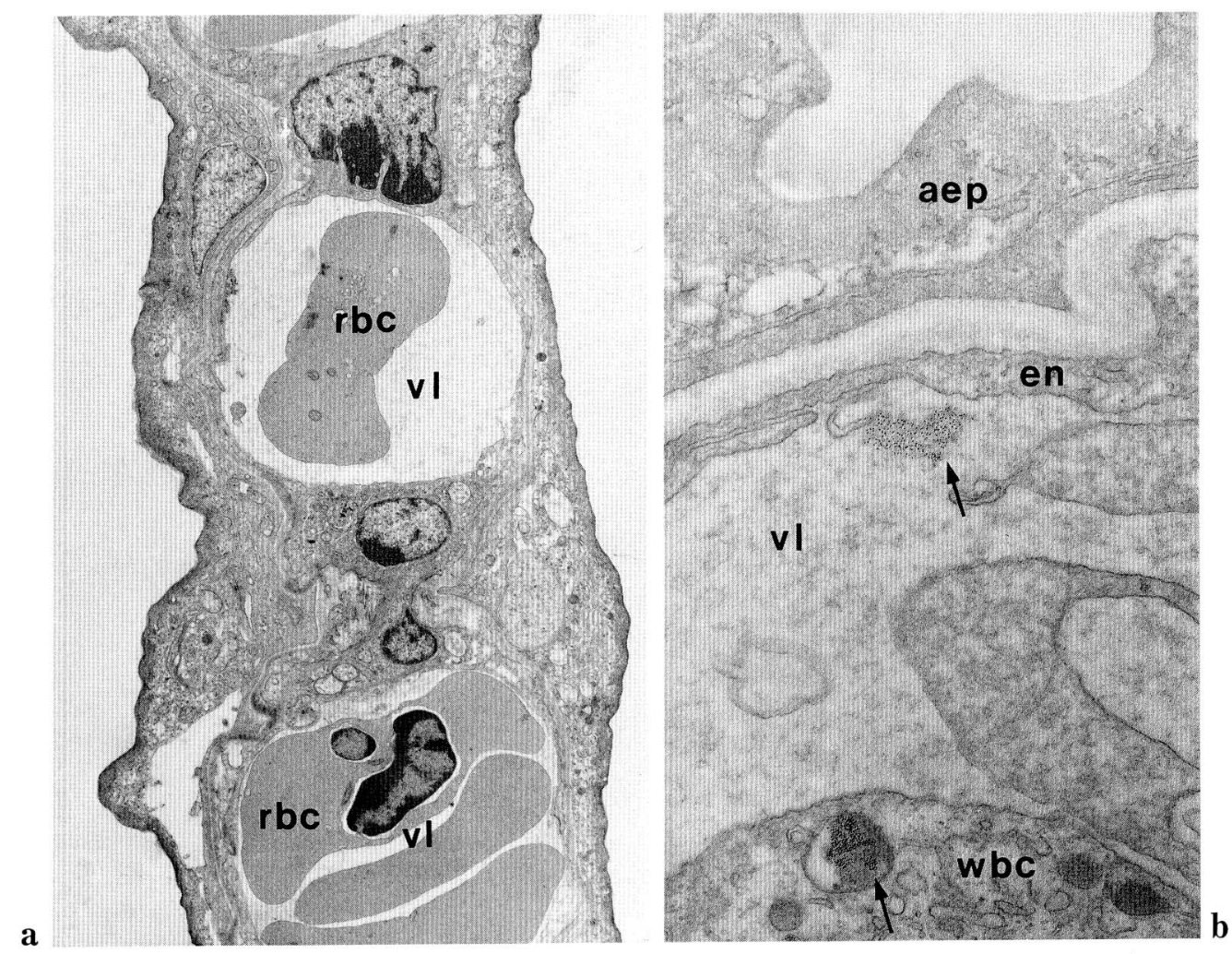

Fig. 5. a. Low-power electron micrograph of a part of a gill taken from a sea-horse sacrificed $24 \mathrm{~h}$ after FS-CF injection. b. Higher magnification of a part of the gill shown in Figure a. Ferritin particles (arrows) are seen within the white blood cells $(w b c)$ and red blood cells $(r b c)$ in the vascular lumen $(v l)$, but none of them is found in the alveolar epithelium $(a e p)$ or interstitial space occupied by a basal lamina. en Endothelium. Stained with uranyl acetate and lead citrate. a: $\times 5,250, \mathrm{~b}: \times 26,000$

fenestrated endothelia (Fig. 6).

The hemopoietic tissue was organized with numerous hemopoietic cells, macrophages, erythroid cells and melano-macrophage centers. All these elements were closely packed within the frameworks of reticular cells and reticular fibers in the hemopoietic tissue. As the macrophages had numerous vacuoles, granules, phagolysosomes, and electron dense materials, their nuclei were pushed to the cell periphery and became irregular in shape (Figs. 2a, b). Phagolysosomes were found to fill a number of degenerated hemopoietic cells which showed degrading nuclei and cytoplasm retaining some original structures (Fig. 3). The melano-macrophage center was a cluster of giant macrophages having large phagolysosomes found in the restricted area of the hemopoietic tissues. Macrophages in the melano-macrophage centers were extremely swollen with the massive phagocytosis of cell debris, electron dense materials and melanin pigments (Figs. 2a, b, 3, 4).
The alveolar capillary of the gill is composed of three layers: the alveolar epithelium, basal lamina and capillary endothelium (Fig. 5a). This structure is very similar to that of the human lung. One hour after the intraperitoneal injection of ferritin, the blood plasma and white blood cells in the alveolar capillaries contained ferritin but no ferritin or iron particles were found in the alveolar epithelia or basal lamina. Even in the specimens sacrificed $24 \mathrm{~h}$ after the intraperitoneal injection of ferritin (Fig. 5b), or in those injected repeatedly, the epithelia and basal lamina had no ferritin or ferric catabolites.

The test for the ionized anionic groups on the aglomerular kidney made with $\mathrm{Fe}-\mathrm{Cac}$ perfusion revealed the dense distribution of anionic groups on the luminal surface of the endothelial cells lining the tubular basement membrane (Fig. 6).

One hour after the intraperitoneal injection of HS-AF or HS-CF, both ferritin particles were found diffusely in the intravascular spaces (Fig. 9). The 

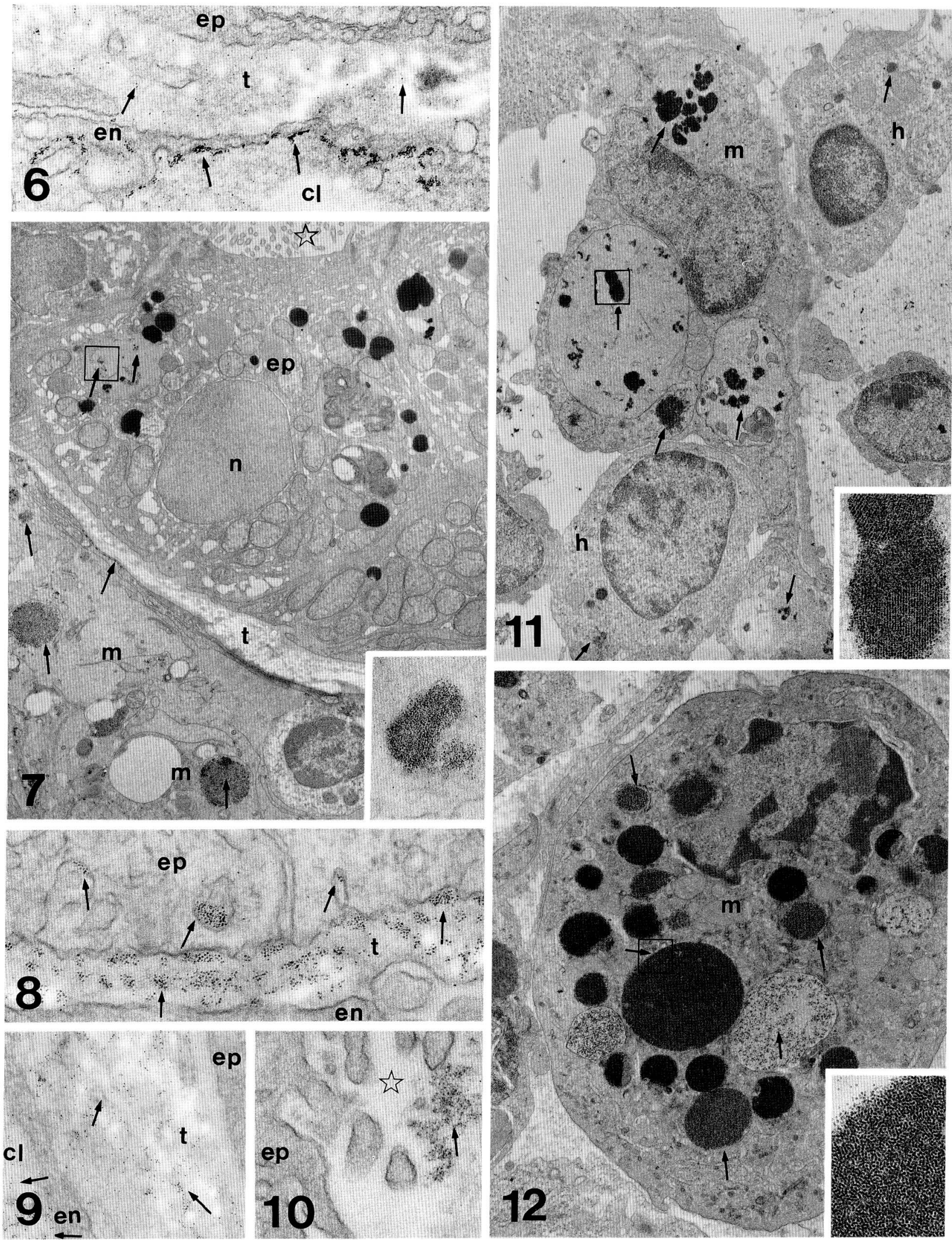

Figs. 6-12. Legends on the opposite page. 
macrophages in the sinusoids took up both HS-AF and HS-CF particles through pinocytosis and accumulated them within phagolysosomes (Figs. 10,11). However, the distribution pattern of HS-AF particles was different from that of HS-CF, the HS-CF particles showing agglomerated clods in which the particles took on a crystalline-arrangement (Fig. 10), while HS-AF particles were distributed diffusely in phagolysosomes forming homogenous masses (Fig. 11). Hemopoietic cells took up HS-CF only.

As for the penetration of ferritin into the tubular basement membrane, HS-CF particles were found within the endothelial fenestration and tubular basement membrane as agglomerated clods (Fig. 8). In contrast, HS-AF particles were distributed diffusely within the tubular basement membrane (Fig. 9). Some particles were found within the pinocytotic vesicles of renal tubular epithelial cells. Photographs showed they were translocated into the epithelial phagolysosomes, and then excreted into the urinary space with or without being degraded into smaller catabolite particles (Figs. 7, 10). However, the numbers of ferritin particles found within the tubular basement membrane and phagolysosomes of the tubular epithelia were much smaller than those in the macrophages. At this stage ferritin particles could hardly be detected within the macrophages of the melanomacrophage centers.

The density of the ferritin particles found in the intravascular spaces, macrophages, tubular basement membrane and within the phagolysosomes of tubular epithelia increased markedly $24 \mathrm{~h}$ after the injection of $0.5 \mathrm{ml}$ of HS-AF or HS-CF. Similar phenomena were also noted in those sacrificed $1 \mathrm{~h}$ after six injections of $0.2 \mathrm{ml}$ of HS-AF or HS-CF at $1 \mathrm{~h}$ intervals, $1.2 \mathrm{ml}$ in total. However, the general distribution pattern of the ferritin particles was nearly the same as that of fish sacrificed $1 \mathrm{~h}$ after injection of 0.5 $\mathrm{ml}$ of ferritin (Figs. 8, 11), though the density and diameter of the phagolysosomes were much larger in the former than the latter (Fig. 11). Moreover, in all cases, few ferritin particles were detected within the macrophages of the melano-macrophage centers.

In specimens sacrificed 14 days after the injections of HS-AF or HS-CF, no ferritin particles and ferric catabolites were detected within the phagolysosomes of macrophages found among the hemopoietic focuses around the tubules. The ferric catabolites were concentrated only within the macrophages of melano-macrophage centers. The diameters of the iron cores of the catabolites were smaller than those detected $1 \mathrm{~h}$ and $24 \mathrm{~h}$ after the ferritin injection,

Fig. 6. Electron micrograph of renal tubules 2 min after perfusion with $\mathrm{Fe}-\mathrm{Cac}$ solution. The picture shows depositions of the colloid particles (arrows) on the luminal surface of the endothelial cells (en) and within the tubular basement membrane $(t) . \mathrm{cl}$ Capillary lumen. For $e p$, see the legend for Figure 2. Unstained section. $\times 40,000$

Fig. 7. Low-power electron micrograph of the renal tissue of the same sea-horse as shown in Figure le. Injected HS-CF particles (arrows) are detected in phagolysosomes of the tubular epithelia (ep), and in phagolysosomes of hemopoietic cells and of the macrophage $(m)$. Inset shows the boxed area of the phagolysosome at higher magnification. Note that the ferritin particles are degraded into small ferric catabolites. For $t$, see the legend for Figure 2. Unstained section. $\times 6,000$, inset: $\times 60,000$

Fig. 8. Electron micrograph showing HS-CF particles in the tubular basement membrane $(t)$ and in tubular epithelium (ep) $24 \mathrm{~h}$ after the injection of $0.5 \mathrm{ml}$ of HS-CF. Notice that particles form an agglomeration and appear in a crystalline pattern. Some particles are taken up through pinocytosis by renal tubular epithelium. For en, see the legend for Figure 5. Unstained. $\times 60,000$

Fig. 9. Electron micrograph of HS-AF particles (arrows) within the tubular basement membrane $(t)$ and capillary lumen $(c l), 1 \mathrm{~h}$ after injection of $0.5 \mathrm{ml}$ of HS-AF. The particles show a diffuse pattern instead of the crystalline pattern of HS-CF. For en, ep, see the legends for Figure 2 and 5. Unstained. $\times 36,000$

Fig. 10. Higher magnification of a part of the urinary lumen ( $₹$ ) of the tubule of the sea-horse shown in Figure 7. Ferritin degraded ferric catabolites (arrow) are excreted from the tubular epithelium $(e p)$. Unstained section. $\times 60,000$

Fig. 11. Electron micrograph of the macrophage $(m)$ and hemopoietic cells $(h)$ from the same section as in Figure 7. Notice how the ingested HS-CF particles (arrows) form aggregates and appear in a crystalline pattern. Inset. A high magnification of the boxed part of the phagolysosome. Stained with uranyl acetate and lead citrate. $\times 10,000$, inset: $\times 60,000$

Fig. 12. Electron micrograph of the macrophage $(m)$ from the same tissue as in Figure 1i. The HS-AF particles (arrows) taken into the phagolysosomes show an accumulative pattern. Inset. A high magnification of the boxed part of the phagolysosome. Stained with uranyl acetate and lead citrate. $\times 15,000$, inset: $\times 60,000$ 

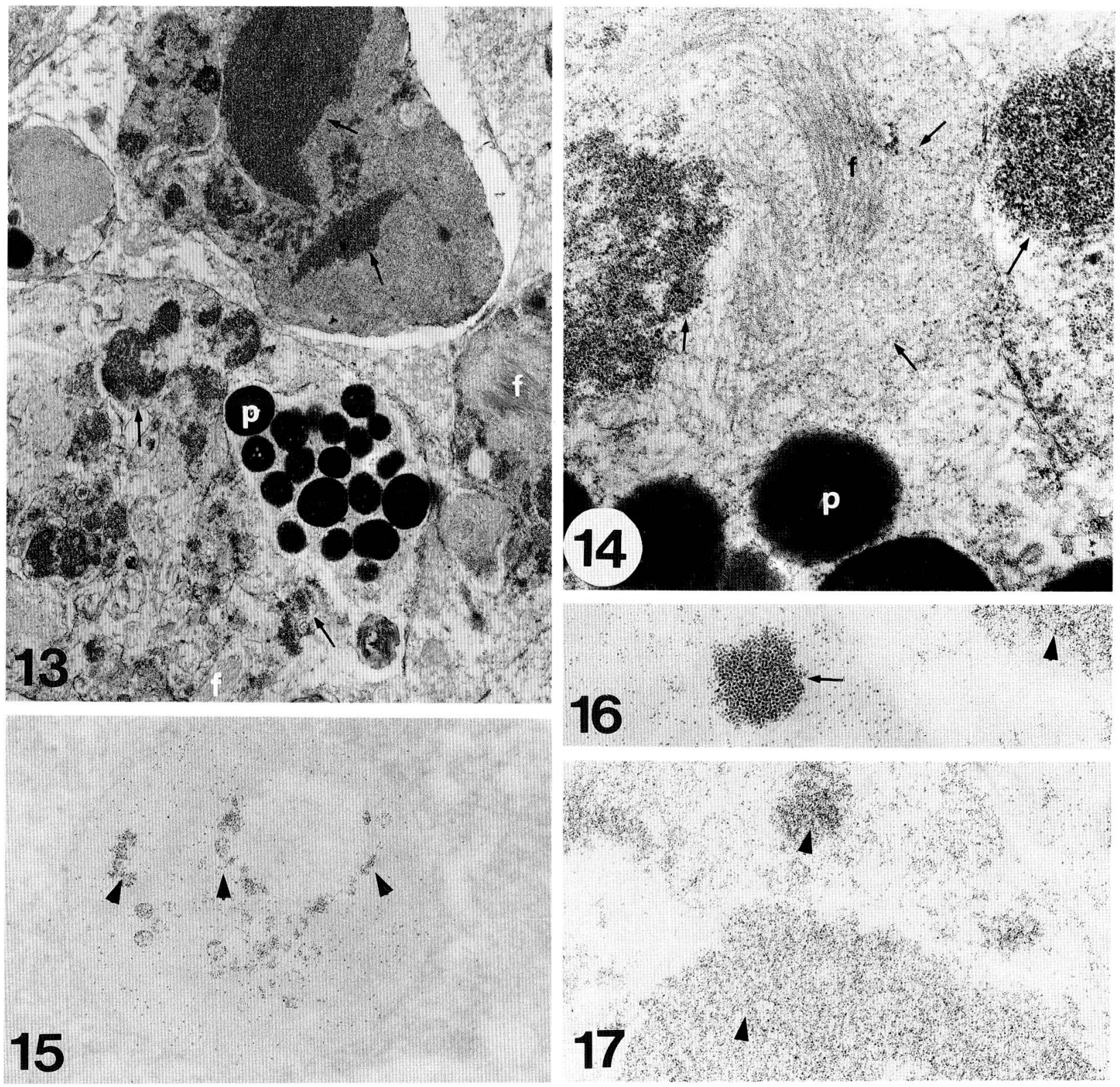

Fig. 13. Low-power electron micrograph of a part of the phagolysosome of the agglomerated macrophage within the melano-macrophage center of the renal tissue taken from the same sea-horse shown in Figure $1 \mathrm{~m}$. Ferric particles (arrows), those catabolites of the injected HS-AF, melanin pigments $(p)$ and fibrous substances $(f)$ are densely packed in the phagolysosomes. Stained with uranyl acetate and lead citrate. $\times 15,000$

Fig. 14. Higher magnification of a part of the phagolysosome of the macrophage observed in the same section shown in Figure 13. The picture shows concentrated ferric particles (arrows), fibrous substances $(f$ ) and melanin pigments $(p) . \quad \times 60,000$

Fig. 15. Higher magnification of an unstained section taken from the same tissue as in Figure 13. Ferric catabolites (arrowheads) are seen in a phagolysosome of the tubular epithelium. The ferric particles are smaller than the iron cores of ferritin. $\times 60,000$

Fig. 16. Higher magnification of the same section as shown in Figure 15. The sizes of the iron cores in phagolysosomes of macrophages are different from one another. Some ferric catabolites (arrowhead) have smaller; the other (arrow) equal in size to those of ferritin. $\times 60,000$

Fig. 17. Higher magnification of ferric particles in a phagolysosome of a macrophage observed within the melano-macrophage center in the same section as shown in Figure 15. Notice the ferric particles (arrowheads) are smaller than the stained ones shown in Figure 14. $\times 60,000$ 
though some iron cores resembled those of ferritin (Figs. 13, 14, 16, 17). Some ferric catabolites were observed within the phagolysosomes in the tubular epithelia (Fig. 14).

\section{DISCUSSION}

The present observations of the aglomerular kidney in the marine teleost revealed that intraperitoneally injected HS-AF and HS-CF are taken up mostly by the macrophages in the sinusoids of hemopoietic tissue around the renal tubules, and that some are excreted through tubular epithelia while the hemopoietic cells take up a small amount of HS-CF only. These results are similar to those obtained with the connective tissue and peritoneal macrophages of the rat by injecting cationic and anionic ferric colloids (SENO et al., 1983b; ONO et al., 1985).

The anionic barrier was found on the luminal surface of the endothelia lining the tubular basement membrane as in the case of the mammalian kidney. But HS-AF as well as HS-CF particles penetrated into the tubular basement membrane, and were taken up by the renal tubular epithelia being transported into their phagolysosomes. HS-CF particles did not adhere to the anionic barrier, probably due to the loss of their cationic charge by binding with anionic serum proteins. HS-AF also did not adhere to the anionic barrier but penetrated into tubular basement membrane, though much less than HS-CF in amount, probably due to its larger repulsive force against the anionic barrier than HS-CF, having minimized electric charges.

Recent experiments using tracer macromolecules with different electric charges have indicated that intravenously given HS-AF is taken up by the mesangial cells of rats, being accumulated in the mesangium (STERZEL et al., 1983b). HS-CF, on the other hand, penetrates into glomerular basement membrane and forms aggregates, appearing in a crystalline pattern (VOGT et al., 1982; TsujII et al., 1985). The present observations gave similar results, i.e., HS-CF particles were detected in a crystalline pattern within the tubular basement membrane, with some in the phagolysosomes of the renal tubular epithelium and the macrophages.

The present histochemical observations showed that the ferritin appeared in macrophages in the sinusoids of hemopoietic tissue 1 to $24 \mathrm{~h}$ after ferritin injection, disappearing by 14 days after the injection. Macrophages within melano-macrophage centers gave no ferritin reaction at any stage, but gave a strong positive ferric reaction, 14 days after ferritin injection. At this stage macrophages in the hemopoietic tissue showed no ferritin reaction, although electron microscopic observation revealed some ferric catabolites of ferritin degradation products, the size of the catabolites being much smaller than that of the ferritin core. However, after degradation of the HS-CF, the catabolites do not take a crystalline pattern. The findings suggest that macrophages laden with ferritin in the sinusoids digest the ferritin and move to accumulate with each other to then form a melano-macrophage center.

These phenomena are quite similar to the results obtained by HUDSON and YofFEY $(1963,1968)$ with the reticulo-endothelial cells in the bone marrow of guinea-pig, STRIKER (1979) on macrophages and mesangium of glomeruli, and by FuJiTA et al. (1983) on Kupffer cells in the livers of mice. Fujita et al. (1983) mentioned, that one month after the injection of Indian ink, large clumps of aggregated Kupffer cells containing numerous carbon-filled vacuoles were distributed in the Disse space and other connective tissue spaces, after which Kupffer cells fused with one another and formed large multinucleated foreign body giant cells with numerous large vacuoles containing densely packed ink materials, being distributed throughout the liver. All these findings indicate that macrophages laden with foreign substances accumulate to one area, forming big clusters.

The term "melano-macrophage center" has long been used by ichthyologists (MACKMULL and MICHELS, 1932; RoBerTS, 1975; Ellis et al., 1978; AGIUS, 1979; AGIUS and ROBERTS, 1981). The melano-macrophage center is formed throughout hemopoietic tissue of both the glomerular and aglomerular kidney as well as the spleen and liver of teleosts, but not in higher vertebrates. The melano-macrophage center is formed by circulating macrophages, replete with particulate matter possibly microbial in origin, or metabolic waste products such as ceroid or hemosiderin, returning selectively to the center, which can therefore be considered metabolic dumps (ELLIS et al., 1978). TsujII and SENO (in preparation) from their ultrastructural study of the aglomerular kidney of the sea-horse, Hippocumpus kuda Bleeker, concluded that the renal macrophages distributed within the sinusoids of hemopoietic tissue phagocytose numerous degenerating hemopoietic cells as well as exo-and endo-genous macromolecules and gather themselves into big clusters. This phenomenon should provide a picture of ineffective erythropoiesis (COOPER, 1977; WINTROBE et al., 1978) and ineffective granulocytosis (PATT and MAlONEY, 1959; Golde and Cline, 1977) or ineffec- 
tive hemopoiesis (WINTROBE et al., 1978) observed in mammals. From this, it is natural that the melanomacrophage centers are found not only in hemopoietic tissue in the kidney but also the liver and spleen. Making this conclusion, it becomes easy to explain the results of the present study, i.e., the intraperitoneally given HS-AF and HS-CF were removed from circulation as exogenous macromolecules through a mechanism similar to the removal of damaged hemopoietic cells in the renal hemopoietic tissue of teleosts.

Acknowledgements. The author is grateful to Prof. T. MurAKAMI, Department of Anatomy of Okayama University School of Medicine and Prof. emer. S. SENo, Director of Shigei Medical Research Institute, for their valuable advice and criticism. Thanks are also due to Dr. H. SHIGEI, Chairman of the Board, Shigei Medical Research Institute, for his unflagging support, to Mrs. S. INOUE, Mrs. F. UEKI and Mr. M. AKITA for their excellent technical assistance, and to the staff of Shima Marineland, Kashikojima, Ago-cho, Mie Prefecture, for providing the specimens.

\section{REFERENCES}

AgIUs, C.: The role of melano-marcophage centres in iron storage in normal and diseased fish. J. Fish Dis. 2: 337-343 (1979).

AgIUs, C. and R. J. Roberts: Effects of starvation on the melano-macrophage centres of fish. J. Fish Biol. 19: 161-169 (1981)

BABIKER, M. M. and J. C. RANKIN : Factors regulating the functioning of the in vitro perfused aglomerular kidney of the anglerfish, Lophius piscatorius L. Comp. Biochem. Physiol. 62A: 989-993 (1979).

Batsford, S. R., H. TakamiYa and A. Vogt: A model of in situ immune complex glomerulonephritis in the rat employing cationized ferritin. Clin. Nephrol. 14: 211216 (1980).

Bertolatus, J. A. and L. G. Hunsicker: Glomerular sieving of anionic and neutral bovine albumins in proteinuric rats. Kidney Int. 28: 467-476 (1985).

Brenner, B. M., M. P. Bohrer, C. BAylis and W. M. DEEN : Determinants of glomerular permselectivity: Insights derived from observations in vivo . Kidney Int. 12: 229-237 (1977).

Cattell, V., A. G. De Urdaneta, S. Arlidge, J. E. Collar, A. Roberts and J. Smith: Uptake and clearance of ferritin by the glomerular mesangium: I. Phagocytosis by mesagial cells and blood monocytes. Lab. Invest. 47: 296-303 (1982).

COOPER, R. A.: Destruction of erythrocytes. In: (ed. by) W. J. Williams, E. Beutler, A. J. Erslev and R. W. RuNDLES: Hematology, 2nd Ed., McGraw-Hill, New York, 1977 (p. 216-230).
Danon, D., L. Goldstein, Y. Marikovsky and E. SKUTELSKY: Use of cationized ferritin as a label of negative charges on cell surfaces. J. Ultrastr. Res. 38: 500-510 (1972).

Ellis, A. E., R. J. Roberts and P. Tytler: The anatomy and physiology of teleosts. In: (ed. by) R. J. RoBERTs: Fish pathology. Bailliere Tindall, London, 1978 (p. 1354).

Ericsson, J. L. E. and B. F. Trump: Electron microscopy of the uriniferous tissue. In: (ed. by) C. RouILlER and A. F. MUlLer: The kidney: morphology, biochemistry, physiology. Academic Press, New York, 1969 (p. 416-447).

Farquhar, M. G., S. L. Wissig and G. E. Palade: Glomerular permeability. I. Ferritin transfer across the normal glomerular capillary wall. J. Exp. Med. 113: 4787 (1961).

Fujita, H., S. Kawamata and K. Yamashita: Electron microscopic studies on multinucleate foreign body giant cells derived from Kupffer cells in mice given Indian ink intravenously. Virchows Arch. A. Cell Pathol. 42: 33-42 (1983).

Golde, D. W. and M. J. Cline: Production, distribution and fate of granulocytes. In: (ed. by) W. J. Williams, E. Beuther, A. J. Erslev and R. W. Rundles: Hematology, 2nd ed. McGraw-Hill, New York, 1977 (p. 699-706)

Goode N. P., A. M. Davison, G. Gowland, S. R. ApariCIO and M. ShIRES: Persistence of inert macromolecules (imposil) in the rat mesangium and glomerular functional disturbance. J. Pathol. 144: 179-187 (1984).

Hickman, C. P., Jr. and B. F. Trump: The kidney. In: (ed. by) W. S. HoAR and D. J. RANDALL: Fish physiology I. Academic Press, New York, 1969 (p. 91-239).

HoAR, W. S.: General and comparative physiology. Prentice-Hall, Englewood Cliffs, 1975 (p. 305-379).

Hudson, G. and J. M. YoffeY: Reticulo-endothelial cells in the bone marrow of the guinea-pig. J. Anat. 97: 409416 (1963).

: Ultrastructure of reticuloendothelia elements in guinea-pig bone marrow. J. Anat. 103: 515525 (1968).

KARNovsky, M. J.: A formaldehyde-glutaraldehyde fixative of high osmolarity for use in electron microscopy (Abstract). J. Cell Biol. 27: 137A (1965).

KEANE, W. F. and L. RAIJ: Impaired mesangial clearance of macromolecules in rats with chronic mesangial ferritin-antiferritin immune complex deposition. Lab. Invest. 43: 500-508 (1980).

- Determinants of glomerular mesangial localization of immune complexes: Role of endothelial fenestrae. Lab. Invest. 45: 366-371 (1981).

Mackmull, G. and N. A. Michels: Absorption of colloidal carbon from the peritoneal cavity in the teleost Tautogolabrus adspersus. Amer. J. Anat. 51: 4-47 (1932).

Michael, A. F., T. E. Nevins, L. RaiJ, W. F. Keane and J. I. Scheinman: Macromolecular transport in the glomerulus: Studies of the mesangium and epithelium in vivo and in vitro. In: (ed. by) B. B. STEIN: Contempo- 
rary issues in nephrology. Churchill Livingstone, New York, 1979 (p. 167-213).

OGAwA, M.: On the aglomerular fishes in Japan and their kidney structures. Zool. Mag. 66: 420-424 (1957).

ONo, T. and S. SEno: Endocytosis of cationic and anionic iron colloid particles by rat macrophages. Acta Histochem. Cytochem. 19: 105-118 (1986).

Ono, T., T. Tsujil and S. Seno: Endocytosis of cationic iron collid particles by rat peritoneal macrophages and the ferritin synthesis: A morphological study. Acta Histochem. Cytochem. 18: 515-524 (1985).

PatT, H. M. and M. A. Maloney: Kinetics of neutrophil balance. In: (ed. by) F. STohlman, Jr. : The kinetics of cellular proliferation. Grune \& Statton, New York, 1959 (p. 201).

Purtell, J. N., A. J. Pesce, D. H. Clyne, W. C. Miller and V. E. Pollak: Isoelectric point of albumin: Effect on renal handling of ablumin. Kidney Int. 16: 366-376 (1979).

Rankin, J. C., I. W. Henderson and J. A. Brown: Osmoregulation and the control of kidney function. In: (ed. by) J. C. Rankin, T. J. Pitcher and R. T. Duggan: Control processes in fish physiology. Croom Helm, London, 1983 (p. 66-88).

Rennke, H. G., R. S. Cotran and M. A. VenkataCHALAM: Role of molecular charge in glomerular permeability: Tracer studies with cationized ferritins. J. Cell Biol. 67: 638-646 (1975).

ROBERTS, R. J.: Melanin-containing cells of teleost fish and their relation to disease. In: (ed. by) W. E. RIBELIN and G. MigAKI: The pathology of fishes. The Univ. Wisconsin Press, Madison, 1975 (p. 399-428).

Seiler, M. W., C. H. Terrell, A. Finnegan, R. B. STERzeL and J. R. Hoyer: Studies of glomerular mesangial uptake and processing of macromolecules: I. Effect of polyvinyl alcohol-induced macrophages on uptake of iron dextran. Lab. Invest. 54: 616-623 (1986).

Seno, S., T. Tsuji, T. ONo and S. Ukita: Cationic cacodylate iron colloid for the detection of anionic sites on cell surface and the histochemical stain of acid mucopolysaccharides. Histochemistry 78: 27-31 (1983a).

Seno, S., T. Ono and T. TsujiI: Macromolecular charge and cellular surface charge in adhesion, ingestion, and blood vessel leakage. Ann. New York Acad. Sci. 416: 410-425 (1983b).

Sharon, Z., M. M. Schwartz and E. J. Lewis: The glomerular localization and transport of aggregated protamine-heparin complexes. Lab. Invest. 37: 43-52 (1977).

Sternberger, L. A., P. H. Hardy, J. J. Cuculis and H. G. MEYER: The unlabeled antibody-enzyme method of immunohistochemistry, preparation and properties of soluble antigen-antibody complex (horseradish peroxidase-anti HRP) and its in identification of spirochets. J. Histochem. Cytochem. 18: 315-333 (1970).

Sterzel, R. B., G. M. Eisenbach, M. W. Seiler and J. R. HoYer: Uptake of polyvinyl alcohol by macrophages in the glomerular mesangium of rats: Histologic and functional studies. Amer. J. Pathol. 111: 247-257 (1983a).

Sterzel, R. B., M. Perfetto, D. Biemesderfer and M. KASHGARIAN: Disposal of ferritin in the glomerular mesangium of rats. Kidney Int. 23: 480-488 (1983b).

Striker, G. E., M. ManniK and M. Y. Tung: Role of marrow-derived monocytes and mesangial cells in removal of immune complexes from renal glomeruli. J. Exp. Med. 149: 127-136 (1979).

Takamiya, H., S. Batsford, R. Kluthe and A. Vogt: Comparison of the handling of ferritin and ferritinprotein conjugates by the glomerular mesangium: Kinetic studies in the rat. Lab. Invest. 40: 18-24 (1979).

Tsuji, T., I. Naito, S. Ukita, T. Ono and S. Seno: The anionic barrier system in the mesonephric renal glomerulus of the arctic lamprey, Entosphenus japonicus (Martens) (Cyclostomata). Cell Tiss. Res. 235: 491-496 (1984a).

anionic barrier system on the mesonephric renal glomerulus of the brown hagfish, Paramyxine atami Dean (Cyclostomi). Anat. Rec. 208: 337-347 (1984b).

Tsuji, T., T. Ono and S. Seno: Protein leakage through glomerular capillaries having the functioning and dysfunctioning anionic barrier. In: (ed. by) S. SENO, A. L. Copley, M. A. Venkatachalam, Y. Hamashima and T. TsujII: Glomerular dysfunction and biopathology of vascular wall. Academic Press, Tokyo, 1985 (p. 121-139).

Vogt, A., H. Bockhorn, K. Kozima and M. SASAKI: Electron microscopic localization of the nephrotoxic antibody in the glomeruli of the rat after intravenous application of purified nephritogenic antibody-ferritin conjugates. J. Exp. Med. 127: 867-878 (1968).

Vogt, A., R. Rohrbach, F. Shimizu, H. TAKamiYa and S. BATSFORD: Interaction of cationized antigen with rat glomerular basement membrane: In situ immune complex formation. Kidney Int. 22: 27-35 (1982).

Wintrobe, M. M., G. R. LeE, D. R. Boggs, T. C. Bithell, J. W. Athens and J. Foerster: Clinical hematology. Lea and Febiger, Philadelphia, 1978 (p. 80-134, 529-565).

ZAmboni, L. and C. DeMartino: Buffered picric acidformaldehyde: A new, rapid fixative for electron microscopy. J. Cell. Biol. 35: 148A (1967).

Dr. Tadashi TsujII

Division of Ultrastructure Research Shigei Medical Research Institute Yamada 2117, Okayama 701-02 Japan

过井 禎

701-02 岡山市山田 2117

重井医学研究所

超微形態部門 